OPEN ACCESS

Edited and reviewed by: Simona Zompi, University of California, San Francisco,

*Correspondence: Yeong Yeh Lee justnleeyy@gmail.com

Specialty section: This article was submitted to Microbial Immunology,

a section of the journal

Frontiers in Microbiology

Received: 07 April 2016

Accepted: 25 July 2016

Published: 08 August 2016

Citation:

Ma ZF, Abdul Majid N, Yamaoka Y and

Lee YY (2016) Corrigendum: Food Allergy and Helicobacter pylori Infection: A Systematic Review.

Front. Microbiol. 7:1232.

doi: 10.3389/fmicb.2016.01232

\section{Corrigendum: Food Allergy and Helicobacter pylori Infection: A Systematic Review}

\author{
Zheng Feei Ma ${ }^{1}$, Noorizan Abdul Majid ${ }^{2}$, Yoshio Yamaoka ${ }^{3,4}$ and Yeong Yeh Lee ${ }^{2 *}$ \\ ${ }^{1}$ Department of Human Nutrition, University of Otago, Dunedin, New Zealand, ${ }^{2}$ School of Medical Sciences, Universiti Sains \\ Malaysia, Kubang Kerian, Malaysia, ${ }^{3}$ Department of Medicine, Gastroenterology and Hepatology Section, Baylor College of \\ Medicine, Houston, TX, USA, ${ }^{4}$ Department of Environmental and Preventive Medicine, Oita University Faculty of Medicine, \\ Yufu, Japan
}

Keywords: Helicobacter pylori, atopic disease, food allergy, allergy, food sensitivity

\section{A corrigendum on}

Food Allergy and Helicobacter pylori Infection: A Systematic Review by Ma, Z. F., Abdul Majid, N., Yamaoka, Y., and Lee, Y. Y. (2016). Front. Microbiol. 7:368. doi: $10.3389 /$ fmicb.2016.00368

Reason for Corrigendum:

Due to an oversight, the first name of the first author was misspelled as Zheng Fei Ma instead of Zheng Feei Ma. The correct name of the first author should be Zheng Feei Ma and has been corrected. The funding information, shown below, was also missing. The authors apologize for the mistakes. These errors do not change the scientific conclusions of the article in any way.

The original article has been updated.

\section{AUTHOR CONTRIBUTIONS}

All authors have contributed substantially to the conception or design of the work, or the acquisition, analysis or interpretation of data for the work: ZM wrote the first draft of the manuscript; NA, YY, and YL revised and provided feedbacks for the manuscript. All authors have drafted and revised the work critically for important intellectual contents. All authors approved the final version to be published. All authors agreed to be accountable for all aspects of the work in ensuring that questions related to the accuracy or integrity of any part of the work are appropriately investigated and resolved.

\section{FUNDING}

This paper has been funded by the Universiti Sains Malaysia (USM) Research University Individual (RUI) grant (reference: 1001/PPSP/812151).

Conflict of Interest Statement: The authors declare that the research was conducted in the absence of any commercial or financial relationships that could be construed as a potential conflict of interest.

Copyright () $2016 \mathrm{Ma}$, Abdul Majid, Yamaoka and Lee. This is an open-access article distributed under the terms of the Creative Commons Attribution License (CC BY). The use, distribution or reproduction in other forums is permitted, provided the original author(s) or licensor are credited and that the original publication in this journal is cited, in accordance with accepted academic practice. No use, distribution or reproduction is permitted which does not comply with these terms. 